\title{
EFFICACY OF A COMPUTER ASSISTED LEARNING PROGRAMME ON THE KNOWLEDGE AND PRACTICE SCORES OF NURSING STUDENTS IN "INTRANATAL \& POSTNATAL CARE" IN A SELECTED INSTITUTION OF NEW DELHI
}

\author{
Nasima Khatoon ${ }^{1}$, Dr Ratna Prakash ${ }^{2}$ \\ ${ }^{1}$ PhD Scholar, Shri Venkateshwara University, Gajroula, U.P,. \\ ${ }^{2}$ Principal, PAL College of Nursing and Medical Sciences Haldwani U.K \\ Corresponding Email: nassu20@gmail.com
}

\begin{abstract}
:
Introduction:- Computer assisted learning is the future, and that future is now. Education, as a process and discipline, is mainly concerned with imparting knowledge, methods of teaching, and providing a conductive learning environment as opposed to informal education and other means of socialization.

Methodology:- Quasi experimental (one group pre-test and post-test) research design was adopted in quantitative approach. Comprehensive Purposive sampling technique was used to obtain an adequate size of the sample. Hundred Nursing students 50 B.Sc $3^{\text {rd }}$ year and 50 B.Sc $4^{\text {th }}$ year were included in the study to achieve the appropriate power of the study. A structured knowledge questionnaire and structured observation checklist were used for data collection.

Setting of the study was selected nursing institution of New Delhi.

Result:- The overall mean and standard deviation pre and post-test knowledge score was found to be $21.43 \pm .48 \& 36.08 \pm .30$. And overall mean and standard deviation pre and post-observation practice score was found to be $65.83 \pm 4.20$ and $85.38 \pm 4.87$. Paired t test shows statistical significance at $\mathrm{p}<0.05$ level.

Conclusion:- In this study the mean post-test knowledge and practice scores were significantly higher than the mean pre-test knowledge and practice scores of the nursing students. This indicated a significant difference between the effectiveness of computer assisted learning in developing nursing students' knowledge and practice score.

Keywords: Efficacy, computer assisted learning programme, Nursing students

1. Introduction

Computer assisted learning (CAL), as the name implies, is the use of electronic devices/computers to provide educational instruction and to learn. Computer assisted learning can be used in virtually all fields of education, ranging from TV/DVD, playlearn program for kindergarten kids to teaching quadruple and bypass surgery techniques in medicine. CAL is developed

by combining knowledge from all fields of education/learning, human computer interaction (HCI) and cognition. ${ }^{1}$

Computer assisted learning (CAL) is also known as computer assisted instruction (CAI). By playing and using materials stored on DVDs, mobile phones, and other web-based resources, learning becomes more attractive and dynamic, and offers the students entertaining avenues to showcase
\end{abstract}


their listening and learning skills. It boosts the students' confidence in solving the tasks they are assigned and therefore improves the quality of what they have learnt. ${ }^{1}$

High quality health care demands a nursing workforce with sound clinical skills. However, the clinical competency of newly qualified nurses continues to stimulate debate about the adequacy of current methods of clinical skills education and emphasizes the need for innovative teaching strategies. $^{2}$

Nurses play an integral role in the healthcare industry, providing care to patients and filling leadership roles at hospitals, health systems and other organizations. But being a nurse is not without its challenges. It's a demanding profession that requires a lot of dedication and commitment to render care in a systematic way, termed as Nursing Process. ${ }^{3}$

Nursing binds human society with a bond of care and affection. Nursing is a calling to care, which offers an oasis of poignant stories and pool of challenges. Despite of urbanization and globalization in India, the healthcare system in the country continues to face formidable changes. It is of paramount importance that all people everywhere should have access to a skilled, motivated and supportive nursing care within a robust healthcare system. The importance of nurses in healthcare should be underlined for attempting to create a better task force for better quality care for all. There are certain challenges which the Nurses in the present healthcare system face. $^{3}$

Rasha Mohamed Essa (2018) conducted a study to determine the effect of computer - based learning on nursing student's knowledge and skills retention regarding placenta examination. A quasiexperimental research design was utilized. The study was conducted at clinical skills obstetric laboratories and the computer laboratory at Faculty of Nursing, Damanhour University. It comprised a random sample of 80 nursing students who were enrolled in the obstetric nursing course during the second semester of academic year (2015-2016). Students were randomly assigned to two groups namely; Computer based Learning (CBL) group and a traditional learning approach group. Two tools were used for data collection Tool (1): Nursing Students' Knowledge concerning Placenta Examination Questionnaire. Tool II: Placenta Examination Performance Observational Check List. Study results revealed a statistically significant difference between the study and control groups in 
relation to their knowledge and clinical performance immediately, one week and one month after teaching sessions $(\mathrm{p}=0.001)$. The study concluded that students using computer-based learning had better knowledge and skills retention than those of the traditional group at all three time periods. It was recommended that computer based learning should be incorporated in obstetric clinical nursing education to increase the level of students' knowledge and clinical performance. ${ }^{4}$

Martin Schittek (2001) stated that since 1980 the amount of medical information has doubled approximately every second year. This implies that oral health students as well as professionals need to manage the flow of information rationally, in order to learn how to undertake evidence-based decision-making for diagnosis and treatment in a given patient situation. Current research indicates that computer connected databases and computer assisted learning (CAL) may enhance learning and provide the clinician with information for decision-making when treating patients.The software will even "step out" from the screen and help the student with clinical procedures. However, at present CAL should not replace traditional education, but rather be used more as a supplement and for self-directed studies. ${ }^{5}$

\section{Objectives of the Study}

1) To examine the level of nursing students' knowledge about the concepts of nursing process.

2) To observe the nursing students' practices of nursing process in an Obstetrical Care set-up.

3) To determine the efficacy of a computer assisted Learning Session on the knowledge and practice scores of nursing students in "Intranatal \& Postnatal Care".

\section{Methodology}

Keeping in the mind the objectives of the study Quasi experimental one group pre and post test evaluative design was used in this study. Comprehensive Purposive sampling technique was used to select 100 $\left(50\right.$ B.Sc $3^{\text {rd }}$ year and 50 B.Sc $4^{\text {th }}$ year) nursing students at selected nursing institution of New Delhi. The tool developed and used for data collection contained baseline data of nursing students, Structured knowledge questionnaire and structured observation checklist were used as research instrument for data collection.

\section{RESULTS}


In this study, out of all nursing students, $66 \%$ did some courses after $12^{\text {th }}$ class while on the other hand (34\%) took direct admission after $12^{\text {th }}$ class in the B.Sc. nursing programme. For maximum numbers of nursing students (84\%) their parents selected nursing as a professional course for them whereas remaining $16 \%$ selected it as a profession by themselves.

Table 1: Mean \pm Sd of pre and post test knowledge and practice scores of nursing students in 'Intranatal \& Postnatal Care'. $\mathrm{n}=\mathbf{1 0 0}$

\begin{tabular}{|l|l|l|l|l|l|}
\hline Variable & $\begin{array}{l}\text { Pre } \\
\text { (Mean } \pm \\
\text { Sd) }\end{array}$ & $\begin{array}{l}\text { Post } \\
\text { (Mean } \pm \\
\text { Sd) }\end{array}$ & $\begin{array}{l}\mathbf{9 5 \%} \\
\text { CI }\end{array}$ & $\begin{array}{l}\text { Diff } \\
\text { Value }\end{array}$ \\
\hline $\begin{array}{l}\text { Knowle } \\
\text { dge } \\
\text { score }\end{array}$ & $21.43 \pm .4$ & $36.08 \pm .3$ & 13.82 & - & $<0.00$ \\
\hline Practice & $65.83 \pm 4$. & 0 & - & 14.6 & 1 \\
score & 20 & $87.38 \pm 4$. & 18.33 & 19.5 & $<0.00$ \\
& & & - & 5 & 01 \\
\hline
\end{tabular}

Paired $t$ test was applied for the data analysis. The mean post test knowledge and practice scores were apparently higher than the pretest knowledge and practice scores.

Mean of pretest knowledge and practice scores was computed as 21.43 and 65.83 and also post test knowledge and practice score as 36.08 and 85.38 . So the mean of post test knowledge and practice score were higher than the mean pretest knowledge and practice scores. The data is statistically significant.

Inference: finding shows that the computer assisted learning was effective in improving the knowledge and practice scores of nursing students.

Something new: - the lesson plan, which is usually used to teach the nursing students duly validated and reliability testing done satisfactorily.

\section{Recommendations}

Based on the findings of the study, the following recommendations are offered for future research:

1. Empowering education facilitates the occupational tasks and improves the competency and professional skills among nurses.

2. The study can be replicated on large sample of GNM nursing students to validate and generalize its finding; a similar study can be undertaken by using other teaching strategies.

3. Several teaching methods can be tried out in teaching Intranatal and postnatal care to make it interesting for students.

\section{CONCLUSION}

Health is not the mere absence of disease and infirmity but a state of complete physical, social and mental wellbeing of an individual and should be a universal human 
right. There must be a high percentage of interpersonal skills in the care of the woman in addition to being technically competent. Evaluation is one of the most critical phases of the nursing process because it supports the basis of the usefulness and effectiveness of nursing practice. Nursing practice is patient-driven and patient-centered. Accordingly, patient satisfaction has been strongly advocated for by nursing professionals worldwide to be an important indicator of quality nursing care delivery. ${ }^{6}$

This study has proved its effectiveness and therefore it can be concluded that the computer assisted learning is highly effective in developing the knowledge and improving the practices in Intranatal and postnatal care.

\section{REFERENCE}

01. James Olorunosebi. Introduction to Computer Assisted Learning (CAL). IT Training. February 23, 2016

02. While Alison. The effect of computer-assisted learning versus conventional teaching methods on the acquisition and retention of handwashing theory and skills in prequalification nursing students: A randomised controlled trial. International Journal of Nursing Studies.2010 Mar;47(3):287-294
03. Chhugani M, James MM. Challenges faced by nurses in India-the major workforce of the healthcare system. Nurse Care Open Acces J. 2017;2(4):112-114.

DOI: $\underline{10.15406 / \text { ncoaj.2017.02.00045 }}$

04. Rasha Mohamed Essa, Noha Mohamed Mahmoud. Effect Of Computer Based Learning On Nursing Students' Knowledge And Skillsretention Regarding Placenta Examination. IOSR Journal of Nursing and Health Science (IOSR-JNHS) e-ISSN: 23201959.p- ISSN: 2320-1940 Volume 7, Issue 1 Ver. II. (Jan.- Feb .2018), PP 83-94 www.iosrjournals.org

05. Martin Schittek, Nikos Mattheos, H. C. Lyon, Rolf Attström. Computer assisted learning. A Review European journal of dental education.2001 December https :// do i.org/10.1034/j.1600$\underline{0579.2001 .050301 . \mathrm{x}}$

06. Mbeinkong Chwinui, Patient satisfaction with intrapartum and postpartum nursing care. Ngwingmechi University of Buea, Cameroon Bachelor in Nursing Sciences (BNS) 2009 